Intecoms: Journal of Information Technology and Computer Science

Volume 2 Nomor 2, Desember 2019

e-ISSN : 2614-1574

p-ISSN : 2621-3249

DOI : https://doi.org/10.31539/intecoms.v2i2.812

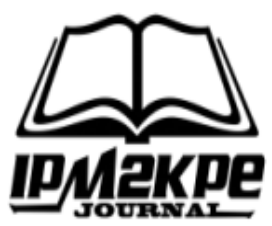

\title{
PENGEMBANGAN SISTEM PENGELOMPOKAN BELAJAR MAHASISWA PADA MATAKULIAH STRUKTUR DATA DENGAN METODE K-MEANS
}

\section{DEVELOPMENT OF STUDENT LEARNING GROUPING SYSTEMS IN DATA STRUCTURE COURSE USING K-MEANS METHOD}

\author{
Yogi Yunefri ${ }^{1}$, Eddisyah Putra Pane ${ }^{2}$ Sutejo $^{3}$ \\ Universitas Lancang Kuning ${ }^{1,2,3}$ \\ yogiyunefri@unilak.ac.id ${ }^{1}$
}

\begin{abstract}
The development of science and technology requires tertiary institutions as formal education institutions, to be able to produce qualified and competent graduates. Learning about higher education needs to be more innovative and creative in producing learning and responsive to labor needs. "Successful constraints of lecturers in teaching Data Structure subjects do not have learning models that approach students with abstract theories that are difficult for students to understand, to overcome these conflicts. learn with the Application of Cooperative Oriented Problems. However, in terms of grouping learning with the application of this method, it still takes a relatively long time to do individual testing several times to find a suitable group, so that the learning grouping is less than optimal. The method used in this study is K-Means Clustering, from the software that was built to help instructors in the subject of data structure in the process of grouping tutoring students. Grouping methods can be implemented to build valid student guidance grouping software.
\end{abstract}

Keywords: Learning Grouping System, Clustering, K-Means

\begin{abstract}
ABSTRAK
Perkembangan ilmu pengetahuan dan teknologi menuntut perguruan tinggi sebagai lembaga pendidikan yang formal, untuk dapat menghasilkan lulusan yang bermutu dan kompeten. Pembelajaran pada perguruan tinggi seharusnya lebih inovatif dan kreatif dalam menghasilkan lulusan serta responsif akan kebutuhan tenaga kerja. "K endala yang dialami dosen dalam mengajar matakuliah Struktur Data adalah belum adanya model pembelajaran yang mendekatkan mahasiswa dengan teori abstrak yang sulit untuk dipahami mahasiswa, untuk mengatasi permasalahan tersebut maka perlu adanya model pembelajaran yang dapat meningkatkan kualitas belajar yang dimiliki mahasiswa dengan cara melakukan pengelompokan belajar dengan penerapan Cooperative Oriented Problem. Akan tetapi dari sisi pengelompokan belajar dengan penerapan metode tersebut masih membutuhkan waktu yang relatif lama yang dilakukan setidaknya beberapa kali pengujian individu untuk menemukan kelompok yang cocok, sehingga pengelompokan belajar tersebut kurang maksimal.Metode yang digunakan dalam penelitian ini adalah K-Means Clustering, dari Perangkat lunak yang dibangun dapat membantu pihak dosen pada mata kuliah struktur data dalam proses pengelompokan mahasiswa bimbingan belajar. Metode clustering dapat diimplementasikan untuk membangun perangkat lunak pengelompokan bimbingan belajar mahasiswa yang valid.
\end{abstract}

Kata Kunci :Sistem Pengelompokan Belajar, Clustering, K-Means

\section{PENDAHULUAN}

Perkembangan ilmu pengetahuan dan teknologi menuntut perguruan tinggi sebagai lembaga pendidikan yang formal, untuk dapat menghasilkan lulusan yang bermutu dan kompeten. Pembelajaran pada perguruan tinggi seharusnya lebih inovatif dan kreatif dalam menghasilkan lulusan serta responsif akan kebutuhan tenaga kerja. Pembangunan dan pengembangan bidang pendidikan diarahkan agar tercapai pertumbuhan ekonomi yang didukung keselarasan antara 
ketersediaan tenaga terdidik dengan kemampuan menciptakan lapangan kerja, kewirausahaan, dan menjawab tantangan kebutuhan tenaga kerja.

Pembangunan dan pengembangan bidang pendidikan dilakukan melalui peningkatan kualitas pendidikan. Pendidikan yang berkualitas akan menghasilkan sumber daya manusia yang berkualitas. Usaha meningkatkan kualitas pendidikan adalah proses yang perlu dilaksanakan secara berkesinambungan dan berkelaanjutan agar tujuan pendidikan nasional dapat tercapai dengan baik. Melalui Undangundang Nomor 20 tahun 2003. Pemerintah memberikan kebijakan dalam meningkatkan kualitas pendidikan nasional melalui pengembangan dan penyempurnaan kurikulum, perbaikan sarana prasana pendidikan, perbaikan sistem evaluasi, pengembangan material dan model pembelajaran.

Berdasarkan hasil survey yang dilakukan pada Program Studi Teknik Informatika di Universitas Lancang Kuning Pekanbaru masih belum memenuhi prinsip-prinsip implementasi pada matakuliah struktur data, mata kuliah struktur data di program studi teknik informatika universitas lancang kuning merupakan mata kuliah pendukung keahlian. Namun berdasarkan data pada sistem informasi akademik Universitas Lancang Kuning, ada kecendrungan penurunan nilai hasl belajar mahasiswa yang mengambil mata kuliah Struktur Data. Hasil pengamatan dikelas ternyata pembelajaran struktur data lebih banyak menggunakan model ceramah dan praktek disertai pemberian tugas, padahal mata kuliah Struktur Data termasuk mata kuliah dibidang pemograman yang banyak membahas teori-teori abstrak. Dalam sebuah program pasti terdapat alur logika yang menyebabkan program tersebut dapat bekerja dengan benar, dan sebagian besar pasti menggunakan pengelolaan data yang terstruktur. Berdasarkan hasil survey menunjukkan bahwa mahasiswa membutuhkan bimbingan yang intensif dan terstruktur dalam proses perkuliahan.

Kendala yang dialami dosen dalam mengajar matakuliah Struktur Data adalah belum adanya model pembelajaran yang mendekatkan mahasiswa dengan teori abstrak yang sulit untuk dipahami mahasiswa, mahasiswa masih cendrung belajar atas petunjuk dari dosen dan bukan inisiatif atas kesadaran sendiri untuk mencari sumber belajar yang tersedia di pustaka maupun internet. Mahasiswa kurang motivasi dan tidak optimal dalam menyelesaikan tugas-tugasnya.

Berdasarkan hasil wawancara dengan dosen yang mengajar Struktur Data pada Fakultas Ilmu Komputer Universitas Lancang Kuning, untuk mengatasi permasalahan tersebut maka perlu adanya model pembelajaran yang dapat meningkatkan kualitas belajar yang dimiliki mahasiswa dengan cara melakukan pengelompokan belajar dengan penerapan Cooperative Oriented Problem (Hamzah dkk., 2019). Akan tetapi dari sisi pengelompokan belajar dengan penerapan metode tersebut masih membutuhkan waktu yang relatif lama yang dilakukan setidaknya beberapa kali pengujian individu untuk menemukan kelompok yang cocok, sehingga pengelompokan belajar tersebut kurang maksimal (Pradnyana \& Permana, 2017). Untuk itu perlu adanya pengembangan terhadap sistem pengelompokan belajar mahasiswa pada materi kuliah Struktur Data salah satunya dengan pengelompokan data mining K-Means Clustering (Poerwanto \& Fa'rifah, 2016). 
Pengelompokan K-Means Clustering merupakan metode analisis kelompok yang mengarah pada pemartisian $\mathrm{N}$ objek pengamatan ke dalam K kelompok (cluster) dimana setiap objek pengamatan dimiliki oleh sebuah kelompok dengan mean (ratarata) terdekat (Yulia \& Setiawan, 2016). Adapun tujuan pengelompokan data ini adalah untuk meminimalkan fungsi objektif yang diset dalam proses pengelompokan, yang pada umumnya berusaha meminimalkan variasi di dalam suatu kelompok dan memaksimalkan variasi antar kelompok (Suprawoto, 2016). Dari hasil pengelompokan menggunakan K-Means Clustering ini didapatlah hasil berupa kelompok mahasiswa yang kompeten, cukup kompeten dan kurang kompeten pada proses pembelajaran mata kuliah struktur data (Syafrianto, 2012).

Algoritma K-Means juga digunakan di dunia kesehatan seperti contohnya Wardhani (2016) mengimplementasikannya untuk pengelompokan pasien pada Puskesmas Kajen Pekalongan. Hasil analisis ini, pengelompokan penyakit berdasarkan usia, jenis kelamin, durasi penyakit dan diagnosa penyakit. Penelitian ini menggunakan alat Rapid Miner 5.3. Berdasarkan data dari pusat klinik Kajen Pekalongan, hasil pengelompokan adalah 376 item dari penyakit akut dan 624 tidak akut dari 1000 total data. Begitu juga dengan Asroni dan Ronald (2015) melakukan clustering mahasiswa berdasarkan nilai akademik dengan Weka.

\section{Adapun metode penelitian dalam penelitian ini adalah sebagai berikut :}

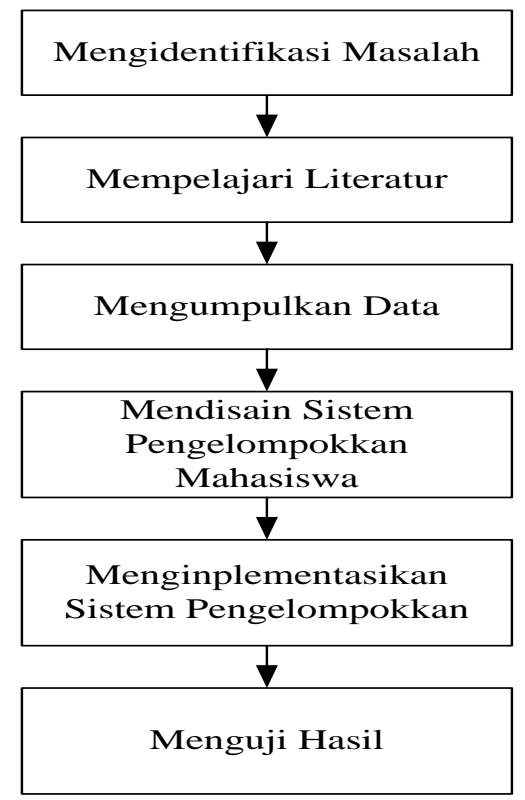

\section{Gambar. 1 Kerangka Kerja}

Pendekatan yang akan digunakan dalam penelitian ini adalah System Development Live Cycle (SDLC) dengan model waterfall. Model waterfall merupakan proses pengembangan perangkat lunak secara bertahap dengan menyelesaikan tahapan-tahapan sebelumnya agar bisa lanjut ke tahapan selanjutnya. Pada penelitian ini tahapan awal adalah mengidentifikasi masalah terlebih dahulu, setelah mengidentifikasi masalah selanjutnya mempelajari literatur-literatur seperti dari buku, artikel dan lainnya. Setelah itu langkah selanjutnya adalah mengumpulkan datadata yang berkaitan dengan penelitian ini. Kemudian langkah selanjutnya mendesain Sistem Pengelompokan Mahasiswa menggunakan K-Means. Selanjutnya mengimplementasikan Sistemnya dan menguji hasilnya.

\section{METODE PENELITAN}

\section{HASILDANPEMBAHASAN}




\section{Analisa Sistem}

Tahap analisa sistem bertujuan sebagai dasar perancangan atau perbaikan sistem yang lama. Dari hasil analisis tersebut dapat dirancang atau diperbaiki menjadi sebuah sistem yang lebih efektif dan efisien. Untuk meningkatkan kecepatan dan keakuratan baik dalam penginputan data, pemrosesan data, serta hasil output nya maka perusahaan memerlukan aplikasi yang lebih efisien mengingat kemajuan teknologi yang semakin pesat maka, perlu adanya sistem pengelompokkan belajar yang nantinya dapat membantu pihak Fakultas Ilmu Komputer khususnya dosen yang mengajar matakuliah Struktur Data.

Analisa sistem ini merupakan penguraian dari suatu implementasi pengelompokkan belajar mahasiswa menggunakan Algoritma K-Means Clustering serta penilaian kompetensi mahasiswa dengan Cooperative Tipe STAD. Dengan menerapkan sistem pengelompokkan belajar ini membantu menentukan kelompok belajar secara merata dengan sistem perhitungan matematis. Perhitungan matematis yang dimaksudkan berupa perhitungan Algoritma K-Means Clustering antara Nilai IPK mahasiswa, Nilai Matakuliah Algoritma dan Pemrograman, serta penilaian Cooperative Tipe STAD pada setiap pertemuan.

Pengembangan

sistem

pengelompokkan belajar mahasiswa pada matakuliah struktur data ini dirancang dengan menggunakan perhitungan Algoritma K-Means Clustering.Pada aplikaksi ini dibutuhkan data akademis mahasiswa yang mengambil matakuliah struktur data di semester genap 2019.Pada setiap pertemuan pada perkuliahan tersebut juga dibutuhkan pula perhitungan nilai Cooperative Tipe STAD.

\section{Analisis Kebutuhan Sistem}

Pembagian kelompok belajar dilakukan dengan menggabungkan nilai variabel dari IPK masing-masing mahasiswa dengan nilai matakuliah Algoritma dan Pemrograman yang sudah didapatkan sebelumnya serta penilaian Cooperative Tipe STAD pada setiap pertemuan. Setelah pengelompokkan didapatkan dari perhitungan Algoritma K-Means Clustering berupa mahasiswa yang sangat berkompeten, mahasiswa yang berkompeten, cukup kompeten dan kurang kompeten, maka tahap selanjutnya adalah pemerataan kelompok dengan melakukan pembagian dalam beberapa kelompok dimana masin-masing kelompok nantinya memiliki mahasiswa yang sangat berkompeten, mahasiswa yang berkompeten, cukup kompeten dan kurang kompeten. Aplikasi mampu memberikan hasil dari analisa berupa pengelompokkan belajar mahasiswa pada matakuliah struktur data sesuai dengan penilaian yang telah didapatkan pada setiap pertemuan.

\section{Praproses Data}

1. Integrasi

Data.Integrasi/penggabungan data untuk pengolahan ataupun perhitungan secara manual menggunakan aplikasi Ms.Excel 2007, yaitu menggabungkan data nilai IPK mahasiswa, nilai matakuliah Algoritma dan Pemrograman mahasiswa, dan penilaian Cooperative Tipe STAD pada setiap mahasiswa yang mengambil matakuliah struktur data pada semester genap 2019.

2. Pembersihan Data

Pembersihan data adalah tahap yang berfungsi untuk menghilangkan data duplikat, tidak konsisten, missing values, dan data yang bersifat outlier dari data mentah yang akan 
diklasterkan. Beberapa langkah yang dilakukan untuk proses pembersihan data.

3. Transformasi Data

Tahapan ini merupakan tahapan dimana data diubah menjadi format/ bentuk yang sesuai untuk dilakukan penggalian data. Karena data sudah sesuai dengan format yang diinginkan yaitu disimpan dalam format data excel (.xls), maka tidak perlu mentransformasikan data tersebut. Data ini berguna untuk melakukan proses perhitungan manual dengan menggunakan Ms.Excel 2007.

\section{Data Hasil Praproses}

Data hasil praproses terdiri dari 2 atribut yang akan diklasterisasikan, yaitu Nilai IPK dan nilai matakuliah Algoritma dan Pemrograman pada setiap mahasiswa, serta penambahan 1 atribut untuk nilai Cooperative Tipe STAD dengan total data sampel sebanyak 40 data atau 1 kelas mahasiswa matakuliah struktur data Fakultas Ilmu Komputer Universitas Lancang Kuning pada semester genap 2019. Tabel berikut menjelaskan atribut-atribut yang akan digunakan untuk klasterisasi dan tampilan beberapa data hasil praproses yang telah dilakukan.

\section{Analisis Pengelompokan Data}

Dalam penelitian ini, dilakukan pengelompokan atau klaster tingkat kompetensi mahasiswa berdasarkan data dari mahasiswa Fakultas Ilmu Komputer Universitas Lancang Kuning yang mengambil matakuliah Struktur Data pada semester genap 2019. Dilakukan pengklasteran data menjadi empat buah klaster, yaitu klaster mahasiswa yang sangat berkompeten, mahasiswa yang berkompeten, cukup kompeten dan kurang kompeten. Jadi pada penelitian ini klaster yang akan dibentuk adalah sebanyak empat kelompok atau nilai $\mathrm{k}=4$. Dimana atribut yang digunakan adalah sebanyak 3 buah atribut yaitu Nilai IPK, Nilai Algoritma dan Pemrograman dan Nilai Cooperative Tipe STAD, jumlah data yang diperoleh sebanyak 40 data. Data tersebut akan digunakan sebagai bahan untuk melakukan proses analisa clustering algoritma K-Means yang dilakukan perhitungan secara manual menggunakan aturan-aturan algoritma $\mathrm{K}$-means yang telah ditetapkan.

\section{Analisa Clustering dengan Algoritma K-Means}

K-Means termasuk dalam metode data mining partitioning clustering yaitu setiap data harus masuk dalam cluster tertentu dan memungkinkan bagi setiap data yang termasuk dalam cluster tertentu pada suatu tahapan proses, pada tahapan berikutnya berpindah ke cluster yang lain. K-Means memisahkan data $\mathrm{ke} \mathrm{k}$ daerah bagian yang terpisah, dimana $\mathrm{k}$ adalah bilangan integer positif. Algoritma K-Means sangat terkenal karena kemudahan dan kemampuannya untuk mengklasifikasi data besar dan outlier dengan sangat cepat (Li, dkk., 2015).

Berikut adalah langkah-langkah

Algoritma K-Means:

1. Menentukan jumlah cluster.

2. Menentukan pusat cluster awal.

3. Menghitung jarak dengan pusat cluster.

4. Pengelompokan data.

5. Penentuan pusat cluster baru.

Algoritma penentuan pusat cluster :

1. Cari jumlah anggota tiap cluster

2. Hitung pusat baru dengan rumus 
Iterasi ke-1

\section{Menentukan Pusat Cluster Awal}

Menentukan centroid awal dilakukan secara acak dari data/objek yang tersedia sebanyak jumlah cluster k. Nilai centroid awal pada penelitian ini dilakukan pemilihan secara acak, dimana jumlah centroid awal dilakukan sebanyak empat centroid awal, nilai untuk $\mathrm{C} 1$ diambil dari baris data D02, nilai C2 diambil dari baris D08, nilai C3 diambil dari baris data D20, nilai $\mathrm{C} 4$ diambil dari baris data D21. Berikut ini nilai centroid awal pada penelitian, $\mathrm{C}$ adalah cluster:

$$
\begin{aligned}
& \mathrm{C} 1=(2.73 ; 3 ; 30) \\
& \mathrm{C} 2=(3.18 ; 2 ; 10) \\
& \mathrm{C} 3=(3.34 ; 3 ; 20) \\
& \mathrm{C} 4=(3.55 ; 3 ; 5)
\end{aligned}
$$

2. Menghitung Jarak dengan Pusat Cluster. Untuk menghitung jarak setiap data yang ada terhadap pusat cluster dalam penelitian ini penulis menggunakan rumus Euclidean Distance

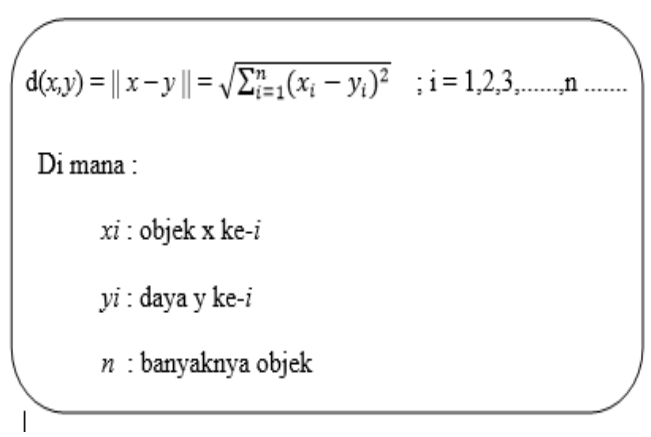

Berikut ini adalah perhitungan jarak dengan Euclidean Distance untuk iterasi 1 dengan centroid 1:

$$
\begin{aligned}
& D 01=\sqrt{(2.89-2.73)^{2}+(4-3)^{2}+(30-20)^{2}}=10.05 \\
& D 02=\sqrt{(2.73-2.73)^{2}+(3-3)^{2}+(20-20)^{2}}=10.00 \\
& D 03=\sqrt{(1.75-2.73)^{2}+(1-3)^{2}+(10-20)^{2}}=20.12 \\
& D 04=\sqrt{(3.27-2.73)^{2}+(4-3)^{2}+(30-20)^{2}}=1.14 \\
& D 05=\sqrt{(1.45-2.73)^{2}+(1-3)^{2}+(30-20)^{2}}=25.11 \\
& \ldots \ldots \ldots \ldots \ldots . . . \\
& D 40=\sqrt{(3.16-2.73)^{2}+(3-3)^{2}+(20-20)^{2}}=20.00
\end{aligned}
$$

\section{Iterasi ke-2}

\section{Penentuan Pusat Cluster Baru}

Tentukan posisi centroid baru dengan cara menghitung nilai rata-rata dari data-data yang ada pada centroid yang sama.
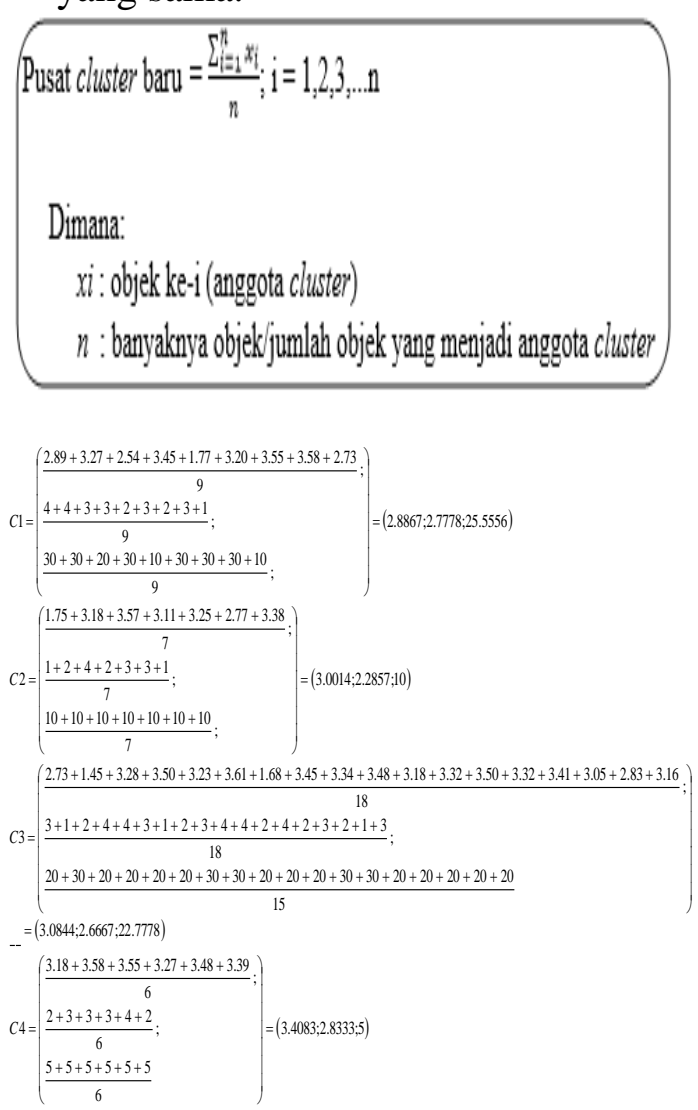


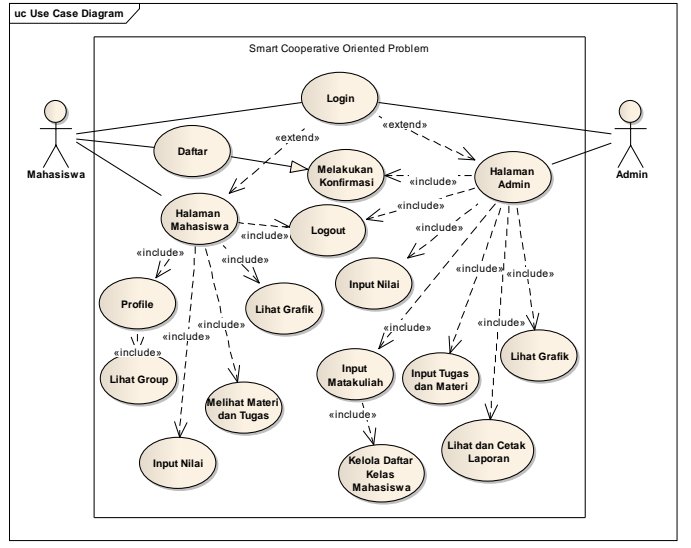

Gambar. 2 Use Case Diagram

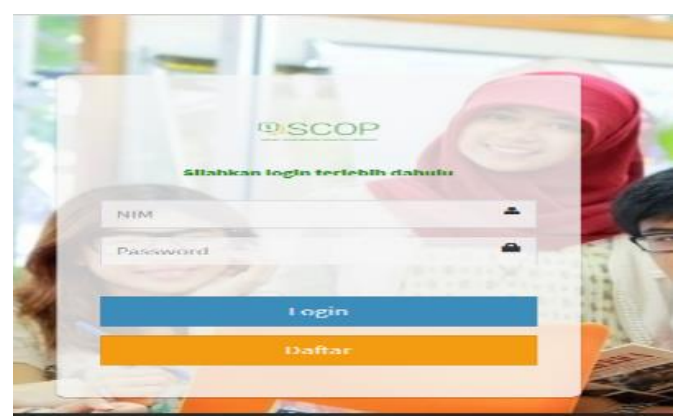

Gambar. 3 Tampilan Halaman Login

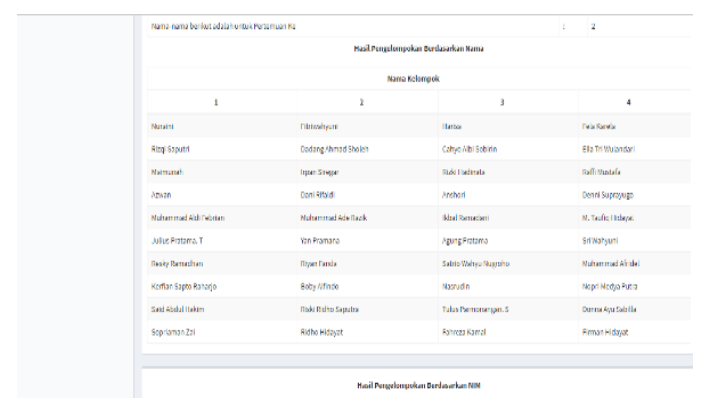

Gambar. 4 Tampilan Halaman Pengelompokan

\section{SIMPULAN}

Berdasarkan hasil yang didapat dalam penelitian ini serta disesuaikan dengan tujuan penelitian maka diperoleh kesimpulan sebagai berikut : 1) perangkat lunak yang dibangun dapat membantu pihak sekolah dalam proses pengelompokan siswa calon peserta bimbingan belajar, 2) metode clustering dapat di implementasikan untuk membangun perangkat lunak pengelompokan siswa calon peserta bimbingan belajar yang valid.

\section{DAFTAR PUSTAKA}

Aditra, P. G. \& Permana, J. A. (2017). Perancangan Sistem Pembagian Kelas Kuliah Mahasiswa dengan Kombinasi Metode K-Means dan K-Nearest Neighbors. EProceedings KNS\&I STIKOM Bali, 285-290. Retrieved from https://knsi.stikom-

bali.ac.id/index.php/eproceedings/ article/view/54

Asroni, A., \& Adrian, R. (2015). Penerapan Metode K-Means untuk Clustering Mahasiswa Berdasarkan Nilai Akademik Dengan Weka Interface Studi Kasus pada Jurusan Teknik Informatika UMM Magelang. Jurnal Ilmiah Semesta Teknika,18 (1), 76-82

Hamzah, M. L., Rukun, K., Fahmi, R., Purwati, A. A., Hamzah., \& Zarnelly, Z. (2019). A Review of Increasing Teaching and Learning Database Subjects in Computer Science, Espacios, 40(26), 6. Retrieved from http://www.revistaespacios.com/a 19v40n26/19402606.html

Li, L., Luo, X., \& Chen, H. (2015). Clustering Students for GroupBased Learning in Foreign Language Learning. International Journal of Cognitive Informatics and Natural Intelligence, 9(2), 5572

Poerwanto, B., \& Fa'rifah, R. Y. (2016). Analisis Cluster Menggunakan Algoritma KMeans, d'ComPutarE. Jurnal Ilmiah Teknologi Informasi

Suprawoto, T. (2016). Klasifikasi Data Mahasiswa Menggunakan Metode K- Means untuk Menunjang Pemilihan Strategi Pemasaran, 
Jurnal Informatika dan Komputer (JIKO), 1(1), 12-18

Syafrianto, A. (2012). Perancangan Aplikasi K-means untuk Pengelompokan Mahasiswa Stmik El-Erhama Yogyakarta Berdasarkan Frekuensi Kunjungan ke Perpustakaan dan IPK. Jurnal Teknologi Informasi dan Ilmu Komputer (FAHMA), http://jurnal.stmikelrahma.ac.id/as sets/file/Andri\%20Syafrianto_stm ikelrahma.pdf

Wardhani, A. (2016). K-Means Algorithm Implementation for Clustering of Patients Disease In Kajen Clinic of Pekalongan. Jurnal Transformatika, 14(1), 3037.doi:http://dx.doi.org/10.26623/ transformatika.v14i1.387

Yulia, D., \& Setiawan, A. (2016). Penerapan Metode Clustering KMeans dalam Penjualan Produk. Jurnal Media Infotama, 12(2), 148-57 